IOS Press

\title{
Discussion
}

\section{Does the production of official statistics need to be a separate branch of Government or should it remain within the Executive Branch of Government?}

\author{
Gerry O'Hanlon \\ Former Director General of the Central Statistics Office, Ireland \\ E-mail: gohanlon2@gmail.com
}

The title of session poses a very clear question, namely: is it necessary for the production and dissemination of official statistics to be undertaken outside the Executive Branch of Government (EBG) in order to ensure, on a sustainable basis, their impartiality and freedom from untoward interference from political, administrative and other stakeholders? This is not a new question but it has become more pertinent in recent years as official statistics have become more relevant to the work of Government and indeed, more generally, to the functioning of society in the modern information age.

I am delighted to have been invited to discuss the contributions of four eminent former colleagues to this debate. They bring a wealth of experience and a wide perspective to the discussion and this is reflected in the papers they have presented. Andreas Georgiou puts forward a strong case for placing the production of official statistics outside the EBG, citing the judicial system as an analogue. The nub of his argument is that professional independence cannot be guaranteed in a robust and sustainable manner unless the statistical agencies themselves are institutionally independent in the fullest sense through their placement outside the EBG. Pali Lehola, in drawing attention to the new challenging environment for statisticians in having to in- teract in real time with politicians and other stakeholders, points to the need for a safe space for them to operate independently. On the other hand, Jean-Luc Tavernier points to the situation in France as providing evidence that official statistics can be produced in a professionally independent manner by agencies operating within the EBG. Dennis Trewin also argues that statistical agencies can function in a professionally independent manner within the EBG and draws attention to the other factors that can improve trust in statistics and guarantee the independence of statisticians.

While there is, therefore, no consensus between the authors on the optimal institutional arrangements for the production of official statistics, all four clearly attach a high priority to compliance with the principle of professional independence and also display a deep understanding of what it entails today to achieve such compliance in practice. I believe that this is firm evidence of the over-riding importance that is now attached to complying with this principle in the design of national statistical systems. In my view this reflects the modern environment in which statisticians must operate, where their outputs are increasingly used in the management and monitoring of our societies and economies. This was not always the case as I can recall no more than twenty-five years ago, when I first 
engaged intensively with these concepts, that the focus was very much on narrower technical concepts such as scientific or statistical independence. The principle of professional independence goes beyond the focus on technical issues, such as the choice of sources and methods, to include the interactions and the relationships with key stakeholders, notably government and policy makers. It is this wider concept of independence that we must keep in mind when we consider the question posed in the session.

In essence, the question is around identifying the best institutional arrangements for statistical agencies in order to ensure that they can comply to the fullest extent in a sustainable manner with the statistical principle of professional independence. To address this question, it is perhaps useful at the outset to look in broad outline at the institutional arrangements that currently apply, or conceivably could apply, in respect of the organization of the production official statistics. I would identify the following four options:

1. NSI (and other producers) part of Ministries (accountable to Minister)

2. NSI a separate independent agency within EBG accountable to Government

3. NSI a separate independent agency within EBG accountable to Parliament

4. NSI a separate independent agency outside EBG

Most National Statistical Institutes (NSIs) fit into one of the first three categories above while the fourth is what is proposed as the ideal by Andreas Georgiou. For example, INSEE in France and the ABS in Australia fall into the first category in that they are linked to the Minister of Economy and Finance in France and the Minister for Treasury in Australia. The CSO in Ireland, where the Office is under the aegis of the Prime Minister, to emphasise its independence from Ministries, is an example of a category 2 NSI. ELSTAT in Greece and the ONS, reporting through the UK Statistics Authority to Parliament, fall into the third category. I am not aware of any NSI that currently could be considered as falling into category 4 so, from my perspective, implementing the proposal from Andreas Georgiou would be breaking new ground for the organisation of official statistics!

All other things being equal, it might be conjectured, in line with the reasoning put forward by Andreas Georgiou, that the degree of professional independence is directly linked to the distance that the NSI is removed institutionally from Government. Accordingly, it might be expected that the level and sustainability of professional independence should improve in moving from category 1 to category 2 to category 3 situations. Unfortunately, it is not possible to empirically test this conjecture for a number of reasons. First, it is not possible to make objective comparisons across countries because of different political, administrative, legal and cultural environments. Secondly, as suggested by Jean-Luc Tavernier and Dennis Trewin, a high level of professional independence can be achieved by category 1 NSIs so, therefore, real improvement, if any, may be very marginal and hence difficult to detect. Finally, and perhaps most importantly, other factors may have a significant influence on the degree of professional independence observed. Seltzer in his excellent 1994 paper $^{1}$ identified ten factors which he suggested contributed to maintaining statistical integrity. These were: 1) long tradition of statistical integrity; 2) strong links between statistical user and producer community; 3) uncensored and active journalism; 4) pre-announced schedule of release dates; 5) active professional statistical society encompassing statisticians in government, academia and industry; 6) sound civil service system; 7) laws relating to the independent status of statistical information and operations; 8) location of statistical service within the governmental structure; 9) stature and contractual status of the head of the statistical service; and 10) international support. Many of these are relevant to maintaining and sustaining professional independence and, indeed, most have been mentioned by Dennis Trewin. However, only factors 7 to 9 inclusive are directly related to the institutional status of the NSI in the context of our discussions. It would be difficult, if not impossible, to assess the combined potential impact of the other factors, either in absolute or relative terms, but I believe it is significant enough for them not to be discounted.

In short, I find it difficult to produce evidence to support the assertion by Andreas Georgiou that the independence of a statistical system outside the EBD would be "much more robust" than any system within. Furthermore, I would not agree with his assertion that "the history of official statistics in the last 100 years is replete with better and less well-known incidents of serious challenges to the professional independence of official statistician". Indeed, I would consider that such cases have been relatively few and far between, partic-

\footnotetext{
${ }^{1}$ W. Seltzer, Politics and Statistics: Independence, Dependence or Interaction? United Nations, Department of Economic and Social Information and Policy Analysis, Working paper series No. 6. New York. 1994. Available from: https://unstats.un.org/unsd/statcom/FPSeltzer.pdf.
} 
ularly for countries where there is a strong tradition of independence and trust in the statistical system.

From a practical perspective, there are also some key questions to be considered before placing the statistical system outside the EBG. I would draw attention to three: the status of the statistical system outside the EBG; decentralised production of statistics; and the reliance on legislation to guarantee professional independence.

In many countries agencies within the civil service (i.e. the EBG) enjoy a higher status and power position than those located outside. This can be due to the political and administrative culture and tradition within a state. While the judicial system normally enjoys a high status and respect everywhere, I do not believe that it is a good analogue to cite as there are very particular circumstances applying to its situation. For example, the role and status of the judicial system is often set down in the National Constitution on a par with the other branches of government. Instead, it might be more realistic to look at the situation of regulatory and other agencies that are situated outside the EBG to get a more accurate assessment of how the statistical system might fare.

The vast majority of national statistical systems involve the production of official statistics outside the NSI, in many cases in a decentralised manner by units within government ministries. Typically, the proportion of official statistics accounted for by these decentralised producers can range from 20 to 50 percent. To be consistent with the objective of Andreas Georgiou's proposal, the production of these statistics should also be moved outside the EBG - presumably, to be undertaken as part of an enlarged NSI. While such a change could be envisaged, it would entail a far greater level of disruption than simply changing the institutional status of the NSI. On the other hand, if the NSI moved outside the EBG and the other producers remained within this could lead to additional difficulties in coordinating the National Statistical System in an effective manner.

Andreas Georgiou places a huge emphasis on adopting appropriate legislation to guarantee the professional independence of statistical production under- taken outside the EBG. There is no doubt that such legislation would be absolutely necessary, but the key question is whether it would be sufficient in all cases? I would tend to be somewhat negative on this score as there are many examples of situations where determined politicians and other powerful interest groups have circumvented, or ignored, laws in the pursuit of their ends. Indeed, even the judicial systems have not been immune from attacks on their independence in some countries! Moreover, I would also suggest that countries with a high regard for, and compliance with, the law are more likely to be able to guarantee the professional independence of their statistical systems irrespective of the institutional setting.

In conclusion, I believe that there is insufficient evidence available to justify the need to move the production of official statistics outside the EBG in order to guarantee professional independence in a robust and sustainable manner. Many countries have national statistical systems, operating in the EBG, that have been fully compliant with the principle of professional independence over prolonged periods and would have little, if anything, to gain from such a move. Irrespective of the institutional setting, incidents will occur from time to time where the independence and integrity of the statistical system may be challenged - all public authorities, not just statistical agencies, are exposed to such challenges and, in my opinion, there is no universal safeguard that will guarantee immunity. I would support Dennis Trewin in calling for the development of strategies to cope with such challenges when they arise in order to minimise any negative impact. As a final comment, I would suggest that the role and status of the Head of the NSI is often critical in defending the professional independence of the statistical system. In my view there would be merit in examining how the institutional and operational independence of the Head might be enhanced in parallel with that of the overall statistical system. The visibility of the Head is also very important and I would favour adopting titles such as National Statistician or Australian Statistics in order to achieve greater public recognition and acceptance of the role. 